\title{
Neuroimaging of Brain Development - Discovering the Origins of Neuropsychiatric Disorders?
}

$\mathrm{R}$ ecent discoveries by prominent neuroimaging scientists (1) claim that many of the adult neuropsychiatric disorders, such as schizophrenia, have their origin during brain development. Most of these disorders have no distinct neuropathological features, or the features described after years of disease are nonspecific and influenced by years of medication. Advanced neuroimaging, using magnetic resonance imaging combined with sophisticated mathematically-based image analysis tools, have given scientists the opportunity to study the disease early in its presentation, or even before clinical manifestations, in families with high risk of disease development. With this approach, researchers have been able to define Endophenotypes, or brain structural features, of specific diseases such as schizophrenia, ADHD or bipolar disorders and autism. Young schizophrenic patients showed a loss of gray matter in comparison with age-matched controls, and siblings of patients showed a similar trend to reduced cortical and cerebellar gray matter and hippocampal volume, which indicates underlying genetic predisposition to disease Serial studies of both cortical gray matter volume, as well as of gray matter surface, have allowed researchers to follow human brain development in vivo (2). The dramatic increase of cortical gray matter, both antenatally during the third trimester of pregnancy and throughout the early years of childhood, is an expression of rapid brain growth (3) The organization of cortical lamination and establishment of millions of synapses, which is genetically controlled, along with distinct environmental influences such as placental insufficiency leads to smaller brains in the newborn with a loss of cortical gray matter volume and smaller hippocampi (4). From detailed cohort studies of normal children and adolescents we know that cortical growth in adolescents enters into a plateau phase after which gray matter starts to decline in volume (2). This is thought to be an expression of the higher complexity and functional synaptic pruning that takes place during this time. Recent data from researchers at UCLA (1) and National
Institutes of Health (5) now indicate that in children and adolescents with neuropsychiatric disorders these normal anatomic developmental processes are disrupted. A loss of gray matter during adolescence occurs in young schizophrenic patients exceeding that of normal teenagers. This indicates that the developmental trajectory of brain development has been altered in these young patients, either by a distinct abnormality of the pruning process or by earlier developmental alterations. A decreased overall gray matter growth in early development would link the occurrence of schizophrenia to pathologies occurring during pregnancy. Poor birth weight has been clearly identified as a risk factor for schizophrenia in later life. Changes in cortical development during adolescence are not only markers of neuropsychiatric disorders, but also indicate structural changes underlying IQ development. Highly intelligent children have thinner cortical frontal gray matter in infancy but express steeper and longer increase in cortical thickness during adolescence (6). Despite impressive new knowledge in the area of neuroimaging, caution should be used in applying these findings directly for diagnostic purposes as disease expression in neuropsychiatric disorders is multifactorial. - Petra S. Ḧ̈ppi

\section{REFERENCES}

1. Sun D, Stuart GW, Jenkinson M, Wood SJ, McGorry PD, Velakoulis D, van Erp TG Thompson PM, Toga AW, Smith DJ, Cannon TD, Pantelis C 2008 Brain surface contraction mapped in first-episode schizophrenia: a longitudinal magnetic resonance imaging study. Mol Psychiatry (in press, 8 July 2008; doi: 10.1038/mp. 2008.34)

2. Giedd JN 2008 The teen brain: insights from neuroimaging. J Adolesc Health 42:335-343

3. Hüppi PS, Warfield S, Kikinis R, Barnes PD, Zientara GP, Jolesz FA, Tsuji MK, Volpe JJ 1998 Quantitative magnetic resonance imaging of brain development in premature and mature newborns. Ann Neurol 43:224-235

4. Lodygensky GA, Seghier ML, Warfield SK, Tolsa CB, Sizonenko S, Lazeyras F, Huppi PS 2008 Intrauterine growth restriction affects the preterm infant's hippocampus. Pediatr Res 63:438-443

5. Sporn AL, Greenstein DK, Gogtay N, Jeffries NO, Lenane M, Gochman P, Clasen LS, Blumenthal J, Giedd JN, Rapoport JL 2003 Progressive brain volume loss during adolescence in childhood-onset schizophrenia. Am J Psychiatry 160:2181-2189

6. Shaw P, Greenstein D, Lerch J, Clasen L, Lenroot R, Gogtay N, Evans A, Rapoport J, Giedd J 2006 Intellectual ability and cortical development in children and adolescents. Nature 440:676-679 